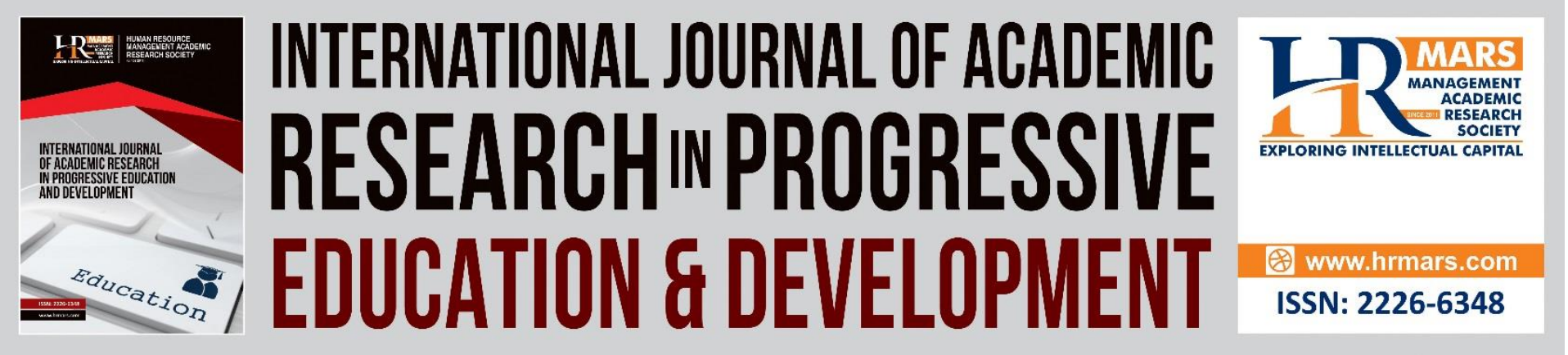

\title{
The Sports Participation Trend among Malaysians by Gender, Ethnic and Age Group
}

Gunathevan Elumalai, Sharifah Mamat, Vellapandian Ponnusamy, Mohd Salleh Aman \& Farhan Mat Arisah

To Link this Article: http://dx.doi.org/10.6007/IJARPED/v11-i1/12288

DOI:10.6007/IJARPED/v11-i1/12288

Received: 18 December 2021, Revised: 20 January 2022, Accepted: 05 February 2022

Published Online: 26 February 2022

In-Text Citation: (Elumalai et al., 2022)

To Cite this Article: Elumalai, G., Mamat, S., Ponnusamy, V., Aman, M. S., \& Arisah, F. M. (2022). The Sports Participation Trend among Malaysians by Gender, Ethnic and Age Group. International Journal of Acdemic Research in Progressive Education and Development, 11(1), 994-1002.

Copyright: (C) 2022 The Author(s)

Published by Human Resource Management Academic Research Society (www.hrmars.com)

This article is published under the Creative Commons Attribution (CC BY 4.0) license. Anyone may reproduce, distribute, translate and create derivative works of this article (for both commercial and non-commercial purposes), subject to full attribution to the original publication and authors. The full terms of this license may be seen at: http://creativecommons.org/licences/by/4.0/legalcode

Vol. 11(1) 2022, Pg. 994 - 1002

http://hrmars.com/index.php/pages/detail/IJARPED

JOURNAL HOMEPAGE

Full Terms \& Conditions of access and use can be found at http://hrmars.com/index.php/pages/detail/publication-ethics 


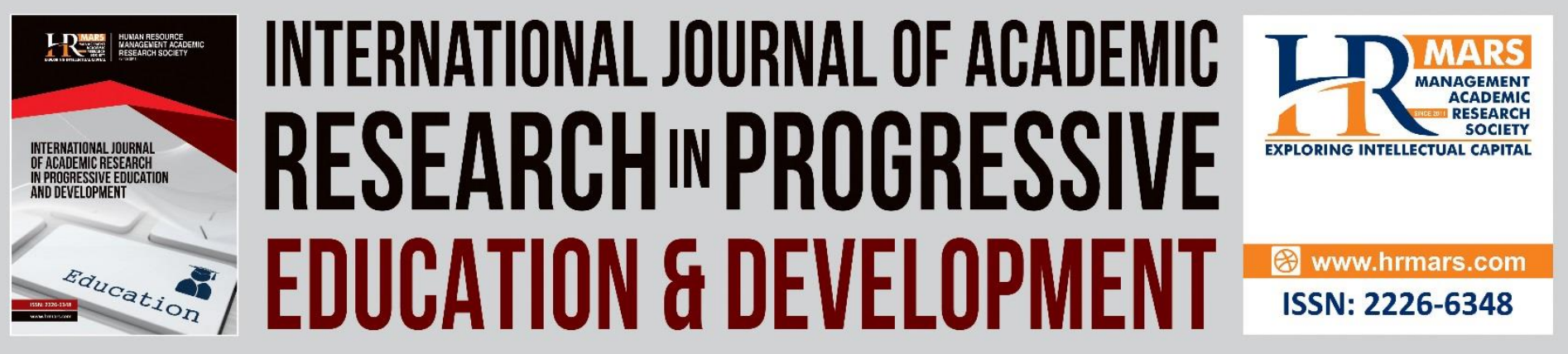

\title{
The Sports Participation Trend among Malaysians by Gender, Ethnic and Age Group
}

Gunathevan Elumalai ${ }^{1}$, Sharifah Mamat ${ }^{2}$, Vellapandian Ponnusamy², Mohd Salleh Aman ${ }^{3}$ \& Farhan Mat Arisah²

${ }^{1}$ Sultan Idris Education University, Tanjung Malim, Perak, Malaysia, ${ }^{2}$ Institute for Youth Research, Ministry of Youth and Sports, Putrajaya, Malaysia, ${ }^{3}$ University Malaya, Sports

Centre

Corresponding author: gunathevan@fsskj.upsi.edu.my

\begin{abstract}
The national Health Morbidity survey by the Malaysian Health Ministry since 2006 showed the percentage of physically inactive Malaysians is still high. Sedentary lifestyles among Malaysians can contribute to an increase in the prevalence of obesity and have been identified as a key risk factor for cardiovascular diseases. The aim of this survey is to identify the trend of participation in physical activity by gender, ethnic and age group from the year 2018 until 2020. The current choice of activities among Malaysians is also considered in this study. The proportionate random stratified sampling method employed to select the Malaysian population aged 13 years and above with an inclusion criteria "participated at least once a month with minimum duration of 60 minutes in any kind of sports, physical exercise and recreational activities". The Malaysian Sports Culture Index (MSCl'2018), an instrument which was designed by Institute for Youth Research Malaysia (IYRES), used to collect the data. Descriptive analysis showed there were significant differences among gender for all the three years. Male populations' activeness higher than females. The ethnic factor also influences the participation in physical activities especially during Movement Control Order due to pandemic COVID-19. Participation by age group also showed significant differences from 2018 to 2020. The One way ANOVA test showed significant differences between age group and ethnic for all the three years with $p=0.000$. Further analysis on choice of activities revealed that activities such as Badminton, Futsal, Jogging, Walking, Cycling and Hiking have become the preference of the Malaysian Population since the year 2018 until now. As a conclusion, physically active and the prevention measures of sedentary lifestyle are major pillars in reducing the risk of morbidity and mortality among our nations. Creating awareness and making sports a culture in daily life will be a better solution for the current health phenomenon.
\end{abstract}

Keywords: Physical Activity, Sports, Exercise, Recreation, Health, Sedentary Life Style

\section{Introduction}

Sport is good for our life. It will educate us how to rise to a challenge, nurturing the character and discipline that will help our nation get on in life. It encourages us all to lead healthier and 
more active lives. It is good for our economy, strengthens community cohesion and gives our young people new skills for life and work. Above all, sport is fun. It will bring lifelong friendships and enhance physical and mental wellness. Physically inactive become a major threat for our health and increases the risk of obesity, type 2 diabetes, cardio metabolic risk factors and other lifestyle diseases. It's increasing the morbidity and mortality among the general population globally. Sedentary lifestyles among Malaysians can contribute to an increase in the prevalence of obesity and have been identified as a key risk factor for cardiovascular disease. The prevention measures of sedentary lifestyle are major pillars in reducing the risk of cardiovascular diseases (NHSM, 2019). During this pandemic era phenomena obesity with its effects on children's mental and physical health and well-being is an international public health priority. The national Health Morbidity survey by the Malaysian Health Ministry since 2006 showed the percentage of physically inactive among Malaysians is still high. The percentage of overweight and obese also getting higher day by day. In 2006 the physically inactive level was $43.7 \%$ and reduced to $25.1 \%$ in the year 2019 . One out of four adults in Malaysia are not active based on WHO recommendation (NHSM, 2019). 28\% females, 59\% elderly above 75 years old, $39 \%$ students and $27 \%$ Urban Dwellers are physically inactive and categorized in $4^{\text {th }}$ leading risk factor for global mortality (WHO, 2019).

The prevalence of Non Communicable Diseases (NCDs) modifiable risk factors and overweight or obesity and hypertension is alarming in Malaysia. The Malaysian Health Ministry found strong associations between tobacco use, diabetes, alcohol consumption, hypertension, physically inactive, and overweight or obesity with NCDs. The results suggest that the government should prioritize NCDs prevention and control programs, focusing on reducing modifiable risk factors. The health sector alone cannot address the NCDs epidemic in Malaysia (NHMS, 2019).

Obesity has become a national issue in health regardless ethnic and age group in Malaysia. One in two adults in Malaysia are overweight or obese and having abdominal obesity. Childhood obesity has long-term detrimental effects on health, and social and economic consequences. It affects children's psychosocial well-being by reducing self-esteem, quality of life and increasing social stigmatization (Abdul Mutalip, 2020). In order to reduce the prevalence of overweight and obesity among Malaysians, we should reduce the incidence of new cases through prevention, and reduce the number of existing cases through treatment and weight management services. Creating self-awareness will be the effective method to overcome this phenomenon. Self-driven interventions in the healthcare setting can be effective in creating positive anthropometric changes in obese and overweight population. Interventions with components to increase physical activity and healthy eating behaviors in the healthcare setting could be utilized to supplement larger obesity prevention efforts.

According to Ahmad et.al (2021), Age, sex, socio-economic status, lack of social support from parents, family and friends have had an impact on motivation to perform Physical activities on a continuous basis. Also, the lack of awareness, attitudes, and practices of individuals themselves for not being involved in Physical activities has affected their interest in sustainability. The environment also plays an important role, such as inadequate facilities and facilities, as well as an unsuitable place or setting that is unconducive and a neighborhood that does not take care of lifelong healthy lifestyle. Regular practice of physical activities such as sport games, exercise and recreational activities improves important aspects in a person's 
health and wellbeing. However, the impact depending on the type of activity or exercise, its intensity, frequency, and duration, has different effects on the human body (Fernandez et.al., 2017).

Thangiah et. al (2021), conducted a longitudinal assessment between lifestyle-related risk factors and a composite cardiovascular disease (CVD) risk index among adolescents in Malaysia. This study revealed that trend in body fat among female adolescents in Malaysia found increases in body fat from $25 \%$ at 13 years to $29 \%$ at 15 years and $28 \%$ at 17 years. Besides that, physical fitness scores were found to be higher among male compared to female adolescents. In addition, the mean score of physical activity in this study was consistently in the lowest category (less than 2.33) among female adolescents from 13 to 17 years. In terms of sitting activities (at least $3 \mathrm{~h}$ of sitting activity in a usual day), the prevalence was higher among females at $52.3 \%$ whereas male at $\mathbf{4 7 . 9 \%}$. A further analysis showed that ethnicity played an important role in determining the overall risk of CVD among adolescents. This study found that compared to Malays, Chinese adolescents were more likely to develop CVD over time. From this study, none of the parental socioeconomic status were found to contribute to CVD risk. The researchers concluded that the lack of participation in outdoor activities due to cultural constraints and low quality physical education during school could perhaps be the reason for the sedentary behaviors.

Saad et. al (2021), screened women with different level of physical activities to determine the relationship between physical activity and cardiovascular risk factors by evaluating the level of physical activity, cardiovascular risk factors, and the cardiopulmonary function among 63 low-income housewives in Kuala Lumpur. The fundamental physiological indicators of volunteers, such as blood sugar, body mass index and blood pressure were tested. The findings revealed that most of the subjects had low level of physical activity and prone to cardiovascular diseases. Women who practice a great level of physical activity had lower BMI and body fat percentage. Their physiological indicators were healthier than those with a low amount of physical activity. Its' proven that Physical education programs and sports activities have a significant effect in improving the physical fitness of the human body.

Based on the current situation and findings from various researches by the Health Ministry, Higher Education Institutions and Non-Governmental Organizations (NGO), Institute for Youth Research Malaysia (IYRES), from the Ministry of Youth and Sports initiated the Malaysian Sports Culture Index research in 2018. The findings of this research in the year 2018, 2019 and 2020 showed the sports culture among Malaysians still in the moderate level and needs special considerations to enhance the participation and contributions towards Malaysia as a sporting nation by 2030 (RMK 12, 2021).

Starting from the year 2020, COVID-19 pandemic caused a negative impact on several aspects of lifestyles such as levels of social and physical activities and dietary behaviors. Several studies have shown that during the lockdown participation in physical activity is not as usual and very limited. Weight gain and more unhealthy dietary patterns such as snacking frequently, eating more and also an increase in daily sitting and screen times in front of television, smart devices and laptops (Meiring et al., 2021; Robinson et al., 2021; Schnitzer et al., 2020; Ammar et al., 2020; Ismail et al., 2020; Husain \& Ashkanani, 2020). Considering the consequences and impact of Movement Control Order (MCO) during Pandemic COVID-19, the researchers intended to investigate the trend of participation in physical activity from the year 2018 up to 2020 among the Malaysian population based on gender, ethnic and age 
group. The type of activities which become the preference of Malaysian people also investigated through this study.

\section{Method}

A population based cross-sectional survey was conducted from 2018 until 2020 among Malaysian population aged 13 years and above with an inclusion criteria "participated at least once a month with minimum duration of 60 minutes in any kind of sports, games, physical exercise and recreational activities." The samples of this study were selected using proportionate random stratified sampling method to represent the Malaysian population by referring to Cohens' sampling table (1988). The Malaysian Sports Culture Index (MSCl'2018), an instrument which was designed by Institute for Youth Research Malaysia (IYRES), Ministry of Youth and Sport employed to collect data from targeted respondents based on the objectives of this research. The data were analyzed descriptively to get the frequency and percentage to determine the trend of participation in physical activities by gender, ethnic and age group from the year 2018 to 2020. The choice of activities was also collected through this study to determine the trend of current interest in physical activities among the Malaysian Population.

\section{Findings}

Based on the literature reviews, gender plays a major role in participation in physical activities. Its' proven that the Malaysian population also having the same trend were male population more active compared to females. The percentage of participation in physical activities from the year 2018 to 2020 showed there were no drastic changes among male population even though in 2020 it slightly increased around 3\% compared to previous years. While female participation in physical activities showed a decrease in 2020 around 5\% (Table1). The independent t-test showed t $(8006)=268.08$ (Year 2018); $\mathrm{t}(8467)=277.33$ (Year 2019); $\mathrm{t}(8587)=275.76$ (Year 2020) and $\underline{p}=.000$ for all is very significant. There were significant differences between male and female from the year 2018 to 2020 .

Table 1: Participation by gender

\begin{tabular}{llll}
\hline $\begin{array}{c}\text { Gender } \\
\text { Year }\end{array}$ & $\mathbf{2 0 1 8}$ & $\mathbf{2 0 1 9}$ & $\mathbf{2 0 2 0}$ \\
\hline Male & $59.2 \%$ & $58.9 \%$ & $62.5 \%$ \\
\hline Female & $40.8 \%$ & $41.1 \%$ & $37.5 \%$ \\
\hline
\end{tabular}

Malaysia is a multi-racial country. The population consists of Malay, Chinese, Indian, Sabahan, Sarawakian, Indigenous people and others. Most of them are aware of the importance of physical activity and participating in sports, exercise and recreation activities regularly. Based on the data obtained through this research the Malay, Indian, Sarawakian, Indigenous People and other ethnic showed slight increase in the percentage of participation in the year 2020. Meanwhile the Chinese ethnic population dropped drastically up to 6\% in the year 2020 (Table 2). The One way ANOVA test showed there were significant differences between ethnic groups at the $p$-value $(p<0.05), F(6,7635)=4.95$ (Year 2018); $F(6,8461)=11.43$ (Year 2019); $F(6,8463)=16.48$ (Year 2020) and $p=0.000$. The Post Hoc using Tukey also showed significant differences between the ethnic groups from the year 2018 to 2020. 
INTERNATIONAL JOURNAL OF ACADEMIC RESEARCH IN PROGRESSIVE EDUCATION AND

\section{DEVELOPMENT}

Vol. 11, No. 1, 2022, E-ISSN: 2226-6348 @ 2022 HRMARS

Table 2: Participation by Ethnic

\begin{tabular}{llll}
\hline \multicolumn{1}{c}{\begin{tabular}{c} 
Ethnic \\
\multicolumn{1}{c}{ Year }
\end{tabular}} & $\mathbf{2 0 1 8}$ & $\mathbf{2 0 1 9}$ & $\mathbf{2 0 2 0}$ \\
\cline { 3 - 4 } Malay & $58.6 \%$ & $59.7 \%$ & $62.7 \%$ \\
Chinese & $20.6 \%$ & $20.8 \%$ & $14.7 \%$ \\
Indian & $6.8 \%$ & $6.5 \%$ & $7.4 \%$ \\
Sabahan & $8.6 \%$ & $8.8 \%$ & $7.1 \%$ \\
Sarawakian & $3.8 \%$ & $3.5 \%$ & $4.2 \%$ \\
Indigenous & $0.3 \%$ & $0.3 \%$ & $0.6 \%$ \\
people & & & \\
Others & $1.3 \%$ & $0.3 \%$ & $3.4 \%$ \\
\hline
\end{tabular}

Age factor also contributes towards participation in physical activity. This study conducted among the Malaysian population aged 13 to 60 years above those involved in regular physical activities. Adolescents from 13 years to 19 years showed a good increase up to $3.5 \%$ compared to the year 2019. While the adults aged 20 to 39 years old remain the same from 2018 to 2020. The age group 40 to 59 showed a linear decrease from year 2018 to year 2020. The elderly people above 60 years old remain the same in the year 2019 and 2020 (Table 3). One way ANOVA test showed there were significant differences between groups at the $p$ value $(p<0.05), F(4,7637)=246.75($ Year 2018); $F(5,8462)=140.83$ (Year 2019); $F(5,8464)$ $=84.48$ (Year 2020) and $\underline{p}=0.000$. The Post Hoc using Tukey also showed significant differences between the groups. The younger generation aged 13-19 and 20-29 were more active in physical activities than other age groups.

Table 3: Participation by Age Group

\begin{tabular}{|c|c|c|c|}
\hline \multicolumn{4}{|l|}{ Age } \\
\hline Yea & 2018 & 2019 & 2020 \\
\hline $13-19$ years & 24.3 & 23.3 & 26.7 \\
\hline $20-29$ years & 29.2 & 28.6 & 28.6 \\
\hline 30-39 years & 21.8 & 22.1 & 21.9 \\
\hline $40-59$ years & 20.3 & 16.7 & 14.7 \\
\hline 60 years and above & 4.3 & 5.9 & 5.7 \\
\hline
\end{tabular}

Participation in physical activity usually depends on the interest and trend of the current population. In Malaysia, the Badminton and Futsal games have become the most popular and trend among all the races from the year 2018 up to 2020. Those who exercise regularly prefer to go for jogging and walking rather than other forms of exercises. Cycling and hiking are the most popular recreation activities among Malaysians since 2018 (Table 4). 
INTERNATIONAL JOURNAL OF ACADEMIC RESEARCH IN PROGRESSIVE EDUCATION AND

DEVELOPMENT

Vol. 11, No. 1, 2022, E-ISSN: 2226-6348 @ 2022 HRMARS

Table 4: Choice of activity

\begin{tabular}{lllll}
\hline Year & Activity & & & \\
& Sports & Exercise & & Recreation \\
\hline 2018 & Badminton \& & Jogging & \& & Cycling \& Hiking \\
& Futsal & Walking & & \\
& Badminton \& & Jogging & \& & Cycling \& Hiking \\
& Futsal & Walking & & \\
& Badminton \& & Jogging \\
& Futsal \& & Walking & & \\
& & & & \\
& & & & \\
& & &
\end{tabular}

\section{Discussion}

Generally the participation in physical activities among Malaysians is not satisfactory. Based on the analysis from 2018 to 2020, the percentage of physically inactive among Malaysians is still high and supports the statement of the Health ministry that "One out of four adults in Malaysia are not active based on WHO recommendation" (NHSM, 2019). The influence of gender also proved, where the female population is less active and not involved regularly in physical activities. Female involvement in physical activities is only around $40 \%$. It means most Malaysian females are sedentary and have lifestyle-related risk factors and cardiovascular prevalence is higher compared to males as discussed by Thangiah et.al, (2021). The decrease among females in 2020 was also caused by the impact of Movement Control Order (MCO) during Pandemic COVID-19. Most of the studies proved that participation in physical activity was not as usual and very limited during the lockdown. Snacking frequently, eating more, an increase in daily sitting and screen times in front of television, smart devices and laptops also contributes towards inactive life-style as mentioned by (Meiring et al., 2021; Robinson et al., 2021; Schnitzer et al., 2020; Ammar et al., 2020; Ismail et al., 2020; Husain \& Ashkanani, 2020).

Analysis based on ethnicity found that compared to Malays, Indians and Sarawakians, Chinese participation in physical activity dropped almost $6 \%$ in the year 2020 during Pandemic COVID19. Overall the percentage of physically active Malaysians' by race is not very high and more likely to develop cardiovascular diseases over time. This situation continues since 2018 due to cultural constraints and low quality physical education during school could perhaps be the reason for the sedentary behaviors as stated in the report of National Health Morbidity Survey (NHMS, 2019).

The Malaysian population is aware of the benefits of physical activity for a healthy and active lifestyle. The data from the year 2018 until 2020 showed the participation by age group in physical activities doesn't change much and remains almost the same for all three years. It seems Movement Control Order (MCO) during Pandemic COVID-19 doesn't contribute much to increase participation in physical activity such as simple exercises even though everyone stayed at home. In 2020, there was a slight decrease in the percentage of participation in physical activities because the trend and choice of all physical activities were outdoor based. Malaysian people still prefer to play badminton and futsal, go for jogging and walking. Cycling and hiking are also their favorite activities during the weekend. 


\section{Conclusion}

Millions of Malaysian population play games, do exercise and are involved in recreation activities. But, the percentage of overall participation is still around $50 \%$. Physical education programs and sports activities have a significant effect in improving the physical fitness and wellness of the human body as stated by (Saad et.al., 2021). Special considerations should be given by the government, schools, higher education institutions, sports organizations through education, family programs, or environmental and policy change. The trend of participating in physical activities such as sports, exercises and recreational activities since the year 2018 never changed as expected by the government and stakeholders even though large amounts of money are spent in developing sports culture among the Malaysian population. Creating awareness and enhancing participation in physical activities lifelong will contribute towards Malaysia as a sporting nation by 2030 as stated in the Twelfth Malaysia Plan. (RMK12, 2030). The participation in physical activities should be an individual effort and Malaysian population must aware the benefit of physical fitness towards lifelong wellness. The behavior changes such as recommended in Theory of Planned Behavior should be introduced to the Malaysians since young. The demographical factors stated in this theory plays a major role in enhancing participation in sports and physical activities. Behavioral changes must be planned and practiced continuously to achieve the goal. Motivational factors also influence the regular involvement in sports and physical activities. Intrinsic motivation since young towards participation in physical activities will contribute to the sustainability of fitness level and lifelong wellness.

\section{Acknowledgment}

The authors are grateful to the Malaysian Institute for Youth Research (IYRES), Ministry of Youth and Sports Malaysia, for the financial and expert support to conduct this study and publication.

\section{References}

Abdul Mutalip, M. (2020). National Health and Morbidity Survey (NHMS) 2020: Methodology for a nationwide population-based survey on communicable diseases in Malaysia. International Journal of Infectious Diseases, 101, 356-357. https://doi.org/10.1016/j.ijid.2020.09.935

Ahmad, N., Asim, H. H., Juatan, N., Hipni, N. E., Ithnain, N., Sanusi, A. N. H., Harun, S. N. F., Zakaria, M. R., Jaafar, N., Mohamed, M. H., Suraji, S. H., \& Krishnan, M. (2021). Contributing Factors to Decline in Physical Activity Among Adolescents: A Scoping Review. Malaysian Journal of Social Sciences and Humanities (MJSSH), 6(9), 447 - 463. https://doi.org/10.47405/mjssh.v6i9.998

Fernández, C. J., Quiñones, T. I., Robles, S. N., \& Padilla, S. J. M. (2017). Revisión sistemática sobre los estudios de intervención de actividad física para el tratamiento de la obesidad (Systematic Review of Physical Activity Programs for the treatment of Obesity). Retos, 33, 261-266. https://doi.org/10.47197/retos.v0i33.52996

Ismail, C. L., Osaili, T. M., Mohamad, M. N., al Marzouqi, A., Jarrar, A. H., Abu Jamous, D. O., Magriplis, E., Ali, H. I., al Sabbah, H., Hasan, H., AlMarzooqi, L. M. R., Stojanovska, L., Hashim, M., Obaid, S. R. R., Saleh, S. T., \& al Dhaheri, A. S. (2020). Eating Habits and Lifestyle during COVID-19 Lockdown in the United Arab Emirates: A Cross-Sectional Study. Nutrients, 12(11), 3314. https://doi.org/10.3390/nu12113314 


\section{DEVELOPMENT}

Vol. 11, No. 1, 2022, E-ISSN: 2226-6348 @ 2022 HRMARS

Husain, W., \& Ashkanani, F. (2020). Does COVID-19 change dietary habits and lifestyle behaviours in Kuwait: a community-based cross-sectional study. Environmental Health and Preventive Medicine, 25(1). https://doi.org/10.1186/s12199-020-00901-5

Meiring, R. M., Gusso, S., McCullough, E., \& Bradnam, L. (2021). The Effect of the COVID-19 Pandemic Movement Restrictions on Self-Reported Physical Activity and Health in New Zealand: A Cross-Sectional Survey. International Journal of Environmental Research and Public Health, 18(4), 1719. https://doi.org/10.3390/ijerph18041719

Saat, M. N. Z., Hanawi, S. A. M. F., Farah, N., Amin, M. H., Hanafiah, H., \& Shamsulkamar, N. S. (2021). Relationship between Physical Activity and Cardiovascular Risk Factors: A Cross-Sectional Study among Low-Income Housewives in Kuala Lumpur. International Journal of Environmental Research and Public Health, 18(11), 6090.

https://doi.org/10.3390/ijerph18116090

National Health and Morbidity Survey (NHMS). (2019). (NMRR-18-3085-44207) Noncommunicable diseases, healthcare demand, and health literacy: Key Findings. (2019). Institute for Public Health National Institutes of Health (NIH) Ministry of Health Malaysia.

Robinson, E., Boyland, E., Chisholm, A., Harrold, J., Maloney, N. G., Marty, L., Mead, B. R., Noonan, R., \& Hardman, C. A. (2021). Obesity, eating behavior and physical activity during COVID-19 lockdown: A study of UK adults. Appetite, 156, 104853. https://doi.org/10.1016/j.appet.2020.104853

Schnitzer, M., Schöttl, S., Kopp, M., \& Barth, M. (2020). COVID-19 stay-at-home order in Tyrol, Austria: sports and exercise behaviour in change? Public Health, 185, 218-220. https://doi.org/10.1016/j.puhe.2020.06.042

Thangiah, N., Su, T. T., Chinna, K., Jalaludin, M. Y., Mohamed, M. N. A., \& Majid, H. A. (2021). Longitudinal assessment between lifestyle-related risk factors and a composite cardiovascular disease (CVD) risk index among adolescents in Malaysia. Scientific Reports, 11(1). https://doi.org/10.1038/s41598-021-98127-0

World health statistics. (2019): monitoring health for the SDGs, sustainable development goals. World health Organization. (2019).

https://apps.who.int/iris/handle/10665/324835 